\title{
Mediating effects of lipids on the association between smoking and coronary artery disease risk among Chinese
}

\author{
Wenjing Song ${ }^{1}$, Jieqiong Guan ${ }^{1}$, Pan He${ }^{1}$, Siyu Fan ${ }^{1}$, Hong Zhi ${ }^{2}$ and Lina Wang ${ }^{1 *}$
}

\begin{abstract}
Objective: The mechanism between smoking and coronary artery disease (CAD) remains unclear. It is likely that lipid (including triglycerides (TG), total cholesterol (TC), low density lipoprotein-cholesterol (LDL-C), high density lipoprotein-cholesterol $(\mathrm{HDL}-\mathrm{C}))$ have been functioning as one of the mediators between smoking and the CAD occurrence. The study aimed to investigate the mediating effect of lipid on the relationship between smoking and CAD risk.
\end{abstract}

Methods: The case-control study included 2048 subjects. General linear regression analysis was used to corroborate the association between smoking and lipid levels. Univariate and multivariate logistic regression analysis were performed to reveal the relationship between smoking, lipid and the risk of CAD. Mediation analysis was used to investigate whether the association between smoking and CAD risk was mediated by lipid.

Results: Smoking was found to be associated with the risk of CAD (odds ratio $(O R)=1.34$, 95\% confidence interval $(C \mathrm{I}): 1.05-1.71, P=0.019)$. Regression analysis showed that $\mathrm{TG}, \mathrm{TC}$ and $\mathrm{HDL}-\mathrm{C}$ were associated with $\mathrm{CAD}(\mathrm{OR}=2.69$, 95\%Cl: 2.12-3.40, $P<0.001 ; \mathrm{OR}=0.34,95 \% \mathrm{Cl}: 0.29-0.43, P<0.001 ; \mathrm{OR}=0.37,95 \% \mathrm{Cl}: 0.30-0.47, P<0.001)$. Moreover, the ratio of TG to HDL-C (TG/HDL-C) was also related to CAD (OR=4.45, 95\%Cl: 3.52-5.64, $P<0.001)$. Mediation analysis showed that among the effects of smoking on CAD, 17.52\% was mediated by lipid, in which HDL-C accounted for $11.16 \%$ and TG accounted for $6.36 \%$. Further analysis showed that the effect was also partially mediated by TG/HDL-C, which was accounted for $28 \%$.

Conclusions: Lipid plays a partial mediation on the association between smoking and CAD risk. The study provides a clue on the mediation effect of lipids on the relationship between smoking and CAD risks, which is a novel insight to the progression of CAD.

Keywords: Smoking, Lipid, Coronary artery disease, Mediation analysis, Casual inference

\section{Introduction}

Cardiovascular diseases (CVDs) are the major cause of death in the world and the main obstacle of human sustainable development [1-3]. CAD is the most important component of CVDs, which is considered to be a leading

\footnotetext{
* Correspondence: Inwang@seu.edu.cn

${ }^{1}$ Key Laboratory of Environmental Medicine Engineering, Ministry of Education, Department of Epidemiology \& Biostatistics, School of Public Health, Southeast University, 87 Ding Jiaqiao Rd, Nanjing 210009, China Full list of author information is available at the end of the article
}

public health burden $[4,5]$. It is estimated that in the year 2018, about 720,000 individuals in the United States experienced new coronary events [6]. It was reported that 11 million Chinese suffer from CAD, and the incidence and mortality of CAD are still raising [7]. Therefore, it is very important to explore the influencing factors and pathogenesis of CAD for improve people's quality of life.

Traditional epidemiological studies have shown that dyslipidemia and smoking are associated with the 
development of CAD $[8,9]$. The pathological basis of CAD is atherosclerosis and lipoproteins play critical roles in the process of atherosclerosis [10]. Therefore, an increased level of LDL-C, TC, TG and a decreased level of HDL-C are associated with an increased risk of CAD [11]. A retrospective cohort study found that TG/HDL-C contributed significantly to the prediction of long-term mortality in patients with CAD after undergoing percutaneous coronary intervention [12]. Cigarette smoking causes about 6 million deaths worldwide every year, and CVD accounts for $40 \%$ of all the smoking-related deaths [13]. Cigarettes are a mixture of several toxic chemicals, such as nicotine, carbon monoxide and so on. Heavy smoking is associated with an increased risk of CAD [14]. However, the mechanism by which smoking causes CAD remains unclear. Some studies suggest that lipids might play an important role in the pathway from smoking to CAD progression [6], even if the hypothesis has not been fully proven.

In the field of psychology and other social sciences, a large number of papers analyze the mechanism of independent variables on dependent variables by establish mediating models. Mediation analysis has also been recently applied in the field of epidemiology. Fan Wang et al. [15] found that the association between APOA5 variant and CAD was partly mediated by TG and HDL$\mathrm{C}$ through mediation analysis. Moreover, Tao Wang et al. [16] found that white fibrinogen, blood cells and hs-CRP partially mediate the association between smoking and intima-media thickness by mediation analysis.

Therefore, Mediation analysis was used to explore the association between smoking and CAD. Further analysis to determine whether lipid is a mediator on the association between smoking and CAD among Chinese.

\section{Methods}

\section{Ethics statement}

All participants provided informed consent. This study was approved by the Ethics Committee of Clinic Medical College, Southeast University, Nanjing, China (Project identification code: 81673259, BK20161435).

\section{Study population}

The present study included 1024 CAD patients (cases group) and 1024 non-CAD subjects (control group). CAD group were recruited between September 2011 to December 2018 in ZhongDa Hospital Affiliated to Southeast University, Nanjing, China. Non-CAD group were selected from the healthy people who underwent physical examination from March to April 2019 in Qixia district, Nanjing, China. CAD subjects received quantitative coronary angiography with a cardiovascular measurement system. CAD patients were defined as those having angiographic coronary stenosis of at least $50 \%$ lumen reduction in at least one major epicardial coronary artery.

Information about demographic data, lifestyle and the vascular events history were obtained using a structured questionnaire. Clinical history from each subject, including sex, age, body mass index (BMI), co-morbidities (Hypertension(HBP), Diabetes mellitus(DM)), white blood cells (WBC), bilirubin, smoking and alcohol drinking were collected. Smokers were defined as individuals who smoked at least one cigarette per day for 1 year or more than 1 year, and had not quit before they participated in the study.

\section{Lipid levels detection}

Venous blood samples were taken after after $12-14 \mathrm{~h}$ of fasting. The samples were collected in $0.1 \%$ EDTAcontaining tubes for lipoprotein measurements. The concentrations of TC, HDL-C, LDL-C and TG were determined by standard biochemical methods using a chemistry analyzer (Synchron clinical system LX20, Beckman Coulter Inc., California. USA).

\section{Statistical analysis}

Continuous variables were presented as mean and standard deviation (SD). Categorical variables were expressed by counts and percentages (\%). The one-way analysis of variance and Pearson's $\mathrm{X} 2$ test were conducted to compare the participants' baseline characteristics. The relationship between smoking and lipid was corroborated by general linear regression analysis. To assess the association between lipid, smoking and the risk of CAD, univariate and multivariate logistic regression analysis were performed. In the logistic regression analysis, the continuous variables were divided into the low-level group and the high-level group according to the median of the non-CAD group. Statistical significance was defined as $P<0.05$ (two sides). Analyses were carried out with the SPSS program (V 23.0, SPSS, IBM, Illinois. USA).

To determine whether lipid could mediate the effect of smoking on the CAD risk, the PROCESS procedure in SPSS was used for mediation analysis, where the mediator should be the continuous variable [17]. The mediation analysis model can be represented by the following three regression equations. Equation (1) shows the total effect of $\mathrm{X}$ on $\mathrm{Y}$, Eq. (2) explains the effect of $\mathrm{X}$ on $\mathrm{M}$, Eq. (3) reveals the relationship between $X$ and $Y$ adjusted for $M$ and the association between $M$ and $Y$ adjusted for $X . e_{1}, e_{2}$, and $e_{3}$ are residuals for the respective equations [18]. The mediation analysis in this study was divided into two models (modle1: the mediators were TG and HDL-C; modle2: the mediator was TG/HDL-C). 


$$
\mathrm{Y}=c \mathrm{X}+\mathrm{e}_{1}
$$

$$
\begin{aligned}
& \mathrm{M}=a \mathrm{X}+\mathrm{e}_{2} \\
& \mathrm{Y}=c^{\prime} \mathrm{X}+b \mathrm{M}+\mathrm{e}_{3}
\end{aligned}
$$

\section{Results}

\section{Characteristics of study participants}

1024 CAD and 1024 non-CAD participants were 1:1 matched by age ( \pm 3 years) and gender. The clinical characteristics of the selected subjects are provided in Table 1 . There was no significant difference of the age between the cases and controls $(P=0.303) .32 .62 \%$ of the cases and $25.78 \%$ of the normal controls were smokers. Compared with the control group, the average level of TG among the cases was significantly higher $(P<0.001)$, while the average level of HDL-C among cases were lower than control group $(P<0.001)$, so TG/ HDL-C was a little bit higher among CAD patients $(P<$ 0.001). However, the TC levels in the cases group were relatively lower than those in the control group. In addition, borderline difference of the LDL-C between cases and controls was found $(P=0.086)$. Among the
CAD patients, 59.28 and $84.38 \%$ cases had been treated with statins and antiplatelet drugs, respectively.

\section{Association between smoking, lipids and CAD}

Significant association were observed between smoking, TG, TC, HDL-C, TG/HDL-C and CAD after adjusting for the potential confounders (TG: $\mathrm{OR}=2.69,95 \% \mathrm{CI}$ : $2.12-3.40, P<0.001 ;$ TC: $\mathrm{OR}=0.34,95 \% \mathrm{CI}: 0.28-0.44$, $P<0.001 ;$ HDL-C: $\mathrm{OR}=0.37,95 \% \mathrm{CI}: 0.30-0.47, \quad P<$ 0.001; TG/HDL-C: OR $=4.45,95 \%$ CI: $3.52-5.64, P<$ $0.001)$. Compared with the subjects in the lower levels of TG and TG/ HDL-C, the subjects in the high levels were associated with 1.69 times and 3.45 times increased risk of CAD, respectively. On the other hand, compared with the subjects with lower levels of TC and HDL-C, the risk of CAD in subjects with high levels decreased by 66 and $63 \%$, respectively. No association was observed between the increased level of LDL-C and CAD risk (Table 2).

\section{Association between smoking and lipid levels}

CAD was found to be positively correlated with TG $(\beta=4.845, P<0.001)$ and TG/HDL-C $(\beta=0.121, P=$ $0.024)$, while it was negatively correlated with HDL-C

\begin{tabular}{|c|c|c|c|c|c|}
\hline & & $\begin{array}{l}\text { Total } \\
(N=2048, \%)\end{array}$ & $\begin{array}{l}\text { CAD } \\
(N=1024, \%)\end{array}$ & $\begin{array}{l}\text { Non-CAD } \\
(\mathrm{N}=1024, \%)\end{array}$ & $P$ \\
\hline \multirow[t]{2}{*}{ Gender } & Male & $1024(50)$ & $512(50)$ & $512(50)$ & 1.000 \\
\hline & Female & $1024(50)$ & $512(50)$ & $512(50)$ & \\
\hline Age & Mean $\pm S D$ & $64.21 \pm 7.33$ & $64.38 \pm 7.45$ & $64.04 \pm 7.19$ & 0.303 \\
\hline BMI $\left(\mathrm{kg} / \mathrm{m}^{2}\right)$ & Mean $\pm S D$ & $23.90 \pm 2.73$ & $24.21 \pm 2.66$ & $23.59 \pm 2.77$ & $<0.001$ \\
\hline \multirow[t]{2}{*}{ Smoking } & Yes & 597(29.20) & $334(32.62)$ & $263(25.68)$ & $<0.001$ \\
\hline & No & $1451(70.80)$ & 690(67.38) & $761(74.32)$ & \\
\hline \multirow[t]{2}{*}{ Drinking } & Yes & $277(13.50)$ & $914(89.26)$ & $857(83.69)$ & $<0.001$ \\
\hline & No & $771(86.50)$ & $110(10.74)$ & 167(16.31) & \\
\hline \multirow[t]{2}{*}{ HBP } & Yes & $1194(58.30)$ & 695(67.87) & 499(48.73) & $<0.001$ \\
\hline & No & $854(41.70)$ & $329(32.13)$ & $525(51.27)$ & \\
\hline \multirow[t]{2}{*}{ DM } & Yes & $434(21.20)$ & $269(26.27)$ & 165(16.11) & $<0.001$ \\
\hline & No & $1614(78.80)$ & 755(73.73) & 859(83.89) & \\
\hline WBC $\left(10^{9} / L\right)$ & Mean \pm SD & $6.26 \pm 1.71$ & $6.52 \pm 1.91$ & $6.01 \pm 1.43$ & $<0.001$ \\
\hline Bilirubin(mg/L) & Mean $\pm S D$ & $13.79 \pm 5.76$ & $13.14 \pm 4.99$ & $14.30 \pm 5.39$ & $<0.001$ \\
\hline TG (mmol/L) & Mean \pm SD & $1.44 \pm 0.94$ & $1.65 \pm 1.01$ & $1.22 \pm 0.81$ & $<0.001$ \\
\hline $\mathrm{TC}(\mathrm{mmol} / \mathrm{L})$ & Mean $\pm S D$ & $4.83 \pm 1.10$ & $4.52 \pm 1.12$ & $5.14 \pm 0.98$ & $<0.001$ \\
\hline LDL-C(mmol/L) & Mean $\pm S D$ & $2.68 \pm 0.77$ & $2.71 \pm 0.87$ & $2.65 \pm 0.65$ & 0.086 \\
\hline HDL-C(mmol/L) & Mean $\pm S D$ & $1.31 \pm 0.38$ & $1.21 \pm 0.39$ & $1.42 \pm 0.34$ & $<0.001$ \\
\hline TG/HDL-C & Mean \pm SD & $1.22 \pm 0.98$ & $1.47 \pm 0.99$ & $0.98 \pm 0.91$ & $<0.001$ \\
\hline
\end{tabular}
$(\beta=-0.159, P<0.001)$ (Table 3$)$.

Table 1 Baseline characteristics of CAD patients and Non-CAD

Results are presented as mean \pm SD or $\mathrm{n}(\%)$ $B M I$ body mass index; HBP hypertension; $D M$ diabetes mellitus; $T G$ triglyceride; $T C$ total cholesterol; $L D L-C$ low density lipoprotein-cholesterol; $H D L-C$ high density lipoprotein cholesterol; $W B C$ white blood cells 
Table 2 Multivariate regression analysis on the relationships between smoking, lipid and CAD risk

\begin{tabular}{|c|c|c|c|c|c|c|}
\hline \multirow[t]{2}{*}{ Variable } & \multicolumn{3}{|l|}{ Model 1} & \multicolumn{3}{|l|}{ Model 2} \\
\hline & $\beta$ & OR (95\%Cl) & $P$ & $\beta$ & OR $(95 \% \mathrm{Cl})$ & $P$ \\
\hline BMI $\left(\mathrm{kg} / \mathrm{m}^{2}\right)$ & -0.023 & $0.98(0.79-1.22)$ & 0.836 & 0.013 & $1.00(0.80-1.24)$ & 0.977 \\
\hline Smoking, Y/N & 0.291 & $1.34(1.05-1.71)$ & 0.019 & 0.384 & $1.38(1.08-1.75)$ & 0.01 \\
\hline Drinking, Y/N & -0.705 & $0.49(0.36-0.68)$ & $<0.001$ & -0.709 & $0.48(0.35-0.66)$ & $<0.001$ \\
\hline $\mathrm{HBP}, \mathrm{Y} / \mathrm{N}$ & 0.563 & $1.76(1.43-2.17)$ & $<0.001$ & 0.556 & $1.73(1.40-2.12)$ & $<0.001$ \\
\hline $\mathrm{DM}, \mathrm{Y} / \mathrm{N}$ & 0.300 & $1.35(1.05-1.73)$ & 0.018 & 0.35 & $1.37(1.07-1.76)$ & 0.013 \\
\hline WBC $\left(10^{9} / \mathrm{L}\right), \mathrm{H} / \mathrm{L}$ & 0.220 & $1.25(1.01-1.53)$ & 0.039 & 0.166 & $1.24(1.01-1.52)$ & 0.044 \\
\hline Bilirubin(mg/L), H/L & -1.046 & $0.35(0.29-0.43)$ & $<0.001$ & -0.94 & $0.49(0.40-0.61)$ & $<0.001$ \\
\hline $\mathrm{TG}(\mathrm{mmol} / \mathrm{L}), \mathrm{H} / \mathrm{L}$ & 0.989 & $2.69(2.12-3.40)$ & $<0.001$ & * & * & * \\
\hline TC (mmol/L), H/L & -1.037 & $0.34(0.28-0.44)$ & $<0.001$ & -0.253 & $0.36(0.29-0.44)$ & $<0.001$ \\
\hline $\mathrm{HDL}-\mathrm{C}(\mathrm{mmol} / \mathrm{L}), \mathrm{H} / \mathrm{L}$ & -0.989 & $0.37(0.30-0.47)$ & $<0.001$ & * & * & * \\
\hline $\mathrm{TG} / \mathrm{HDL}-\mathrm{C}, \mathrm{H} / \mathrm{L}$ & * & * & * & 1.415 & $4.45(3.52-5.64)$ & $<0.001$ \\
\hline
\end{tabular}

multivariate regression analysis was performed. The dependent variable was CAD. Modle1: the mediators were TG and HDL-C; Modle2: the mediator was TG/HDLC. Variables showing significance value $<0.05$ in univariate analysis were included in the multivariate analysis. $B M I$ body mass index; $H B P$ hypertension; $D M$ diabetes mellitus; TG triglyceride; TC total cholesterol; HDL-C high density lipoprotein cholesterol; WBC white blood cells

\section{Mediating effect of lipid on the association between smoking and CAD}

Mediating analysis revealed the mediation effect of lipid on the relationship between smoking and CAD. HDLC, TG, TG/HDL-C were considered as the mediators separately. In model 1 , The total direct effect of smoking on CAD was significant $(\beta=0.532$, 95\%CI: $0.273-$ $0.982)$. The association between cigarette smoking and CAD was partly mediated by HDL-C $(\beta=0.072,95 \% \mathrm{CI}$ : $0.002-0.149)$ and TG ( $\beta=0.040,95 \% \mathrm{CI}: 001-0.094)$. So that, HDL-C and TG accounted for 11.16 and $6.36 \%$ on the correlation between smoking and CAD respectively (Fig.1). In addition, TG/HDL-C also partially mediated the effect of smoking on the increased risks of CAD, accounting for a mediation ratio of $28 \%$. The coefficients of direct effect and indirect effect were $0.337(95 \% \mathrm{CI}$ :
0.096-0.577) and 0.113(95\%CI: 0.049-0.202) respectively (Fig.2).

\section{Discussion}

Smoking and dyslipidemia are the traditional risk factors for CAD $[19,20]$. In this study, Mediation model was used to examine whether lipid act as a mediator in the association between smoking and the risk of CAD. Mediation analyses showed that among the effects of smoking on CAD, $17.52 \%$ was mediated by lipid, among which HDL-C and TG accounted for 11.16 and $6.36 \%$, respectively. Further analyses showed that the effect was also partially mediated by TG/HDL-C, which was accounted for $28 \%$.

This research also verified that smoking was associated with the increased risk of CAD, which is consistent with

Table 3 General linear regression on the relationships between smoking and lipid levels

\begin{tabular}{|c|c|c|c|c|c|c|c|c|c|c|}
\hline \multirow[t]{2}{*}{ Variable } & \multicolumn{2}{|l|}{$\mathrm{TG}$} & \multicolumn{2}{|l|}{ TC } & \multicolumn{2}{|l|}{ LDL-C } & \multicolumn{2}{|l|}{$\mathrm{HDL}-\mathrm{C}$} & \multicolumn{2}{|c|}{$\mathrm{TG} / \mathrm{HDL}-\mathrm{C}$} \\
\hline & $\bar{\beta}$ & $P$ & $\beta$ & $P$ & $\beta$ & $P$ & $\bar{\beta}$ & $P$ & $\beta$ & $P$ \\
\hline Gender, M/F & 0.015 & 0.586 & 0.523 & $<0.001$ & 0.276 & $<0.001$ & 0.169 & 0.058 & -0.175 & $<0.001$ \\
\hline Age & 0.001 & 0.746 & 0.003 & 0.411 & 0.002 & 0.316 & -0.003 & 0.218 & 0.001 & 0.721 \\
\hline BMI $\left(\mathrm{kg} / \mathrm{m}^{2}\right)$ & 0.098 & $<0.001$ & 0.019 & 0.041 & 0.017 & 0.008 & -0.021 & $<0.001$ & 0.100 & $<0.001$ \\
\hline Smoking, Y/N & 0.123 & 0.016 & 0.029 & 0.647 & 0.115 & 0.010 & -0.046 & 0.025 & 0.121 & 0.024 \\
\hline Drinking, Y/N & -0.013 & 0.837 & 0.243 & 0.002 & -0.018 & 0.737 & 0.100 & $<0.001$ & -0.107 & 0.101 \\
\hline $\mathrm{HBP}, \mathrm{Y} / \mathrm{N}$ & 0.156 & $<0.001$ & -0.090 & 0.075 & 0.028 & 0.432 & -0.025 & 0.124 & 0.137 & 0.001 \\
\hline $\mathrm{DM}, \mathrm{Y} / \mathrm{N}$ & 0.205 & $<0.001$ & -0.197 & 0.001 & -0.100 & 0.017 & -0.065 & 0.001 & 0.247 & $<0.001$ \\
\hline WBC & 0.064 & $<0.001$ & 0.026 & 0.075 & 0.042 & $<0.001$ & -0.024 & $<0.001$ & 0.066 & $<0.001$ \\
\hline Bilirubin(mg/L) & -0.006 & 0.086 & 0.002 & 0.654 & -0.007 & 0.045 & 0.003 & 0.009 & -0.008 & 0.032 \\
\hline
\end{tabular}

General linear regression was performed. The dependent variable was lipid levels. Mmale; Ffemale; $B M I$ body mass index; $H B P$ hypertension; $D M$ diabetes mellitus; TG triglyceride; TC total cholesterol; HDL-C high density lipoprotein cholesterol; WBC white blood cells 


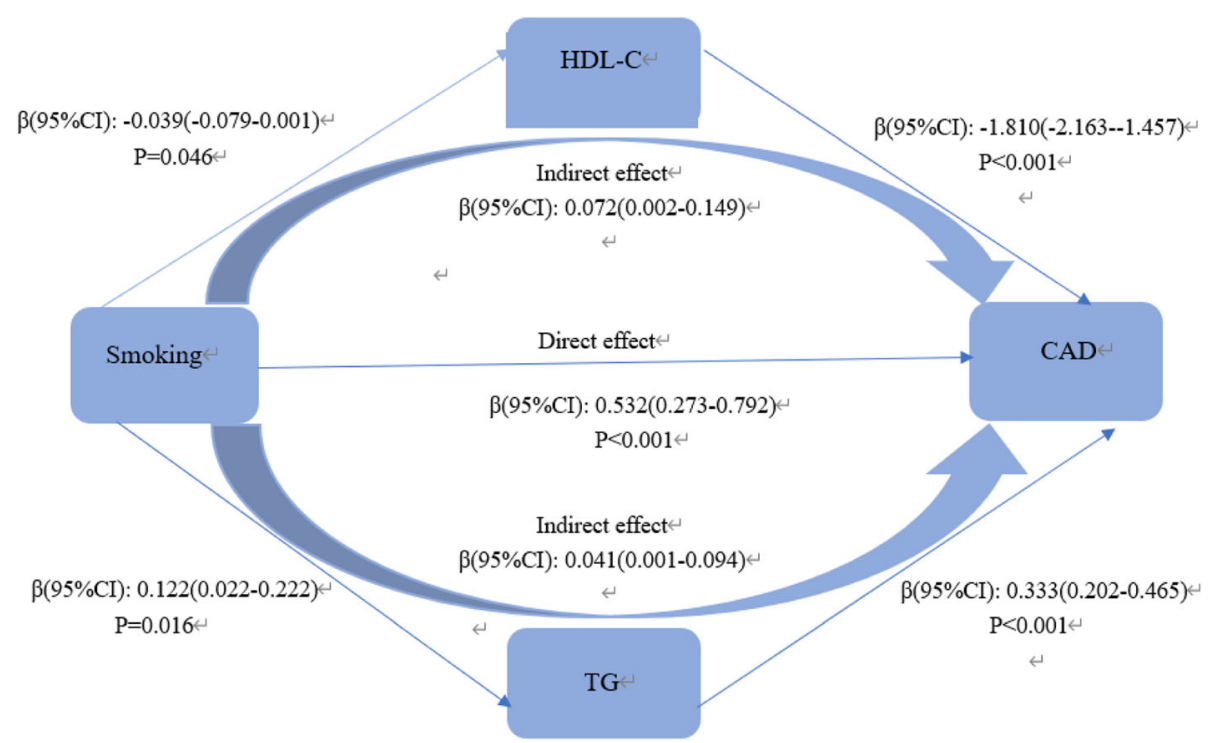

Fig. 1 Mediating effect of TG, HDL-C on the relationship between smoking and CAD

previous studies [21]. In 1958, Hammond EC et al. found that the men who smoked 20 cigarettes per day were twice as likely to die of CAD compared with nonsmokers after tracking 187,783 people for 44 months [22]. In recent years, studies have also reported that smoking is associated with the development of CAD [23-25]. The "INTERHEART study" that was conducted on 29,972 samples also showed that smoking is responsible for the global acute myocardium infarction, and declared that smokers have a 1.95-fold increased risk of non-fatal myocardial infarction compared with Nonsmokers [26].

In addition, lipid also plays a key role in the development of CAD. A series of studies has shown that TG, TC and LDL-C are positively associated with the risk of CAD, while HDL-C is inversely related to the risk of CAD [27, 28]. Furthermore, more and more attention has been paid to the predictive significance of TG/HDL-C on CAD in recent years [29]. A retrospective cohort study found TG/HDL-C to be associated with an increased cardiovascular mortality in female patients on peritoneal dialysis [30]. In our study, the abnormal levels of TG, TC, HDL-C and TG/HDL-C were associated with the CAD risk, but there was a negative correlation between TC and CAD risk, and no association was founded between LDL$\mathrm{C}$ and CAD risk. This phenomenon might be caused by $59.28 \%$ patients in our study who had received statin therapy, which has a significant impact on TC and LDL-C levels so as to caused the underestimation on the lipid levels and CAD risk.

For a long time in the past, the mechanism by which smoking causes CAD was unclear. It was only recently that this mechanism has been generally understood, including oxidative stress, inflammation, lipid modification,

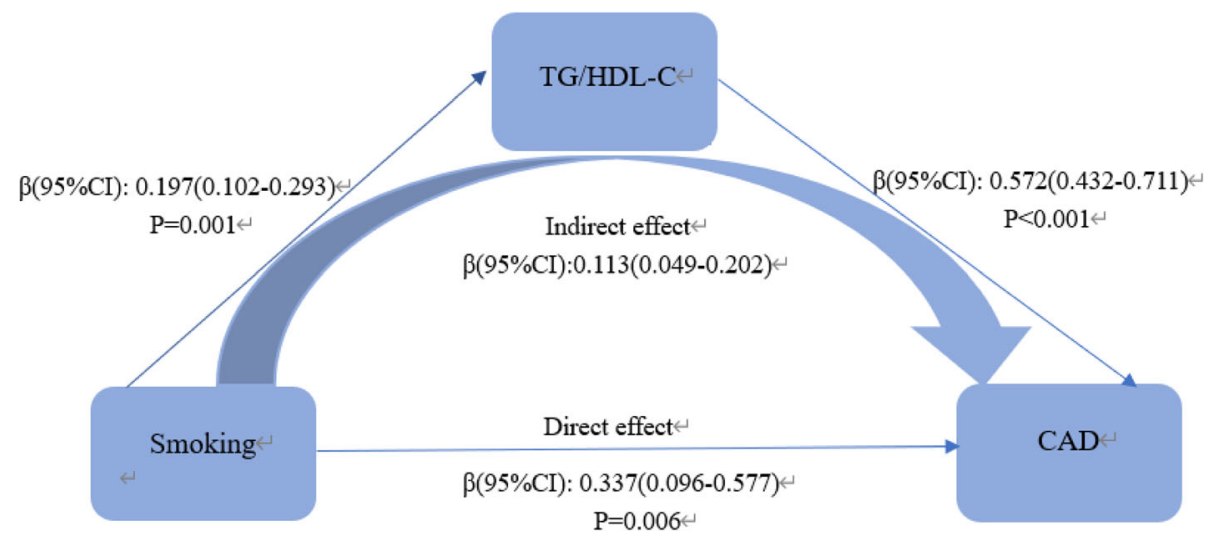

Fig. 2 Mediating effect of TG/HDL-C on the relationship between smoking and CAD 
vascular and endothelial dysfunction and others [31-35]. Traditional epidemiological researches found that lipid might be one of the mediators between smoking and the CAD occurrence. Previous studies showed that Nicotine found in tobacco induces a decrease in MAP kinase phosphatase-1 (MKP1), and leading to the activation of p38 mitogen-activated protein kinases and C-jun $\mathrm{N}$ terminal kinases. These eventually promoting the loss of insulin-mediated lipid inhibition [32]. Therefore, nicotine increases lipolysis, which lead to changes in lipid levels and an increased risk of CAD, but it is still controversial [33]. Indeed, in our study, the abnormal levels of TG and HDL-C accounted for 6.36 and $11.16 \%$ effects on smoking and CAD risk respectively. And also, TG/HDL-C ratio largely mediated the relationship between smoking and CAD risk, which might be of great significance in predicting smoking played important roles in the pathogenesis of CAD.

\section{Study strengths and limitations}

Although there were some strengths in this study, including the relatively large sample size and the mediating analyses to quantify the role of lipids in the association between smoking and CAD, some limitations also should be mentioned. Firstly, all the cases were selected from hospital, some of them might be not newly diagnosed by $C A D$, and they might had taken statins medicines in advance to decrease the lipid levels, which could be underestimated the effects of smoking on lipid levels. In addition, the drug information of the control group could't be obtained due to the shortcomings in the questionnaire, so the study couldn't put the medication information into statistical analysis. Secondly, all the CAD patients were diagnosed by coronary angiography, while the control group were selected from the community without the detection of coronary angiography, and based on the self-report and electrocardiograms examination to exclude the CAD status. This limitation might cause the selection bias of the research. Thirdly, no exact molecular mechanism had been explored in this study. The mediation analysis should be based on reasonable causal hypothesis for verification analysis, and in this original research, the lipid mediators had already been tested playing an important role in the CAD occurrence and progression. Finally, although some confounders have been adjusted in the regression analysis, there may still be some residual confounding factors that had not been adjusted, and this result should be verified by the further researches in multiple regions.

\section{Conclusion}

In summary, the study found a significant association between smoking and CAD among chinese and the association was partially mediated by lipids. The study provides a clue on the mediation effect of lipids on the relationship between smoking and CAD risks, which is a novel insight to the progression of CAD. Further studies should be conducted to verify the findings and determine the elusive mechanism behind them.

\section{Abbreviations}

CVDs: Cardiovascular diseases; CAD: Coronary artery disease; TC: Total Cholesterol; HDL-C: High-density lipoprotein-Cholesterol; LDL-C: Low-density lipoprotein-Cholesterol; TG: Triglyceride; TG/HDL-C: The ratio of TG to HDL-C; BMI: Body mass index; HBP: Hypertension; DM: Diabetes mellitus; WBC: White blood cells

\section{Authors' contributions}

Wenjing Song, Lina Wang contributed to study design, Wenjing Song. Jiegiong Guan, Pan He, Siyu Fan, Hong Zhi collected the clinical data of patients and analyzed the data. Wenjing Song wrote the manuscript and Lina Wang were involved in manuscript revision. All authors have read and agree to the manuscript as written.

\section{Funding}

This study was partly supported by the National Natural Science Foundation of China (81673259), Natural Science Foundation of Jiangsu Province, China (BK20161435).

\section{Availability of data and materials}

Not applicable.

\section{Competing interests}

None.

\section{Author details}

${ }^{1}$ Key Laboratory of Environmental Medicine Engineering, Ministry of Education, Department of Epidemiology \& Biostatistics, School of Public Health, Southeast University, 87 Ding Jiaqiao Rd, Nanjing 210009, China. 2Department of Cardiology, ZhongDa Hospital, Southeast University, Nanjing 210009, China.

Received: 28 April 2020 Accepted: 16 June 2020

Published online: 23 June 2020

\section{References}

1. Organization WHO. The top 10 causes of death. https://www.who.int/newsroom/fact-sheets/detail/the-top-10-causes-of-death. Accessed 12 Apr 2020

2. Organization WHO. Major NCDs and their risk factors. https://www.who.int/ ncds/introduction/en/. Accessed 12 Apr 2020.

3. Benjamin EJ, Muntner P, Alonso A, et al. Heart disease and stroke statistics2019 update: a report from the American Heart Association. Circulation. 2019;139:56-528.

4. Gaziano TA, Pagidipati N. Scaling up chronic disease prevention interventions in lower- and middle-income countries. Annu Rev Public Health. 2013;34:317-35.

5. Wirtz PH, von Kanel R. Psychological stress, inflammation, and coronary heart disease. Curr Cardiol Rep. 2017;19:111.

6. Benjamin EJ, Virani SS, Callaway CW, et al. Heart disease and stroke Statistics-2018 update: a report from the American Heart Association. Circulation. 2018:137:67-492

7. Shengshou $H$, Runlin $G$, Lisheng $L$, et al. China cardiovascular disease report 2018 summary. Chin Circulation J. 2019;34:209-20.

8. Kopin L. C. Lowenstein, Dyslipidemia. Ann Intern Med. 2017;167:81-96.

9. Hackshaw A, Morris JK, Boniface S, et al. Low cigarette consumption and risk of coronary heart disease and stroke: meta-analysis of 141 cohort studies in 55 study reports. Bmj. 2018;360:j5855.

10. Ahotupa M. Oxidized lipoprotein lipids and atherosclerosis. Free Radic Res. 2017:51:439-47.

11. Castelli WP, Anderson K, Wilson PW, et al. Lipids and risk of coronary heart disease. The Framingham Study. Ann Epidemiol. 1992;2:23-8.

12. Dai, X.Y, Y.Y, Zheng J-NT, et al. Triglyceride to high-density lipoprotein cholesterol ratio as a predictor of long-term mortality in patients with 
coronary artery disease after undergoing percutaneous coronary intervention: a retrospective cohort study. Lipids Health Dis. 2019;18:210.

13. Athyros VG, Katsiki N, Doumas M, et al. Effect of tobacco smoking and smoking cessation on plasma lipoproteins and associated major cardiovascular risk factors: a narrative review. Curr Med Res Opin. 2013;29: 1263-74.

14. Salahuddin S, Prabhakaran D, Roy A. Pathophysiological mechanisms of tobacco-related CVD. Glob Heart. 2012;7:113-20

15. Wang $F$, Wang IZ, Ellis $S$, et al. Analysis of causal effect of APOA5 variants on premature coronary artery disease. Ann Hum Genet. 2018;82:437-47.

16. Wang $\Pi$, Jiang $C Q, X u L$, et al. The mediating role of inflammation in the association between cigarette smoking and intima-media thickness: The Guangzhou biobank cohort study. Medicine (Baltimore). 2020;99:e19207.

17. Preacher KJ, Hayes AF. SPSS and SAS procedures for estimating indirect effects in simple mediation models. Behav Res Methods Instrum Comput. 2004:36:717-31.

18. Vlente MJ, Pelham WE, Smyth $\mathrm{H}$, et al. Confounding in statistical mediation analysis: what it is and how to address it. J Couns Psychol. 2017;64:659-71.

19. White J, Swerdlow DI, Preiss D, et al. Association of Lipid Fractions with Risks for coronary artery disease and diabetes. JAMA Cardiol. 2016;1:692-9.

20. Snaterse M, Deckers JW, Lenzen MJ, et al. Smoking cessation in European patients with coronary heart disease. Results from the EUROASPIRE IV survey: a registry from the European Society of Cardiology. Int J Cardiol. 2018;258: $1-6$.

21. Rigotti NA, Pasternak RC. Cigarette smoking and coronary heart disease: risks and management. Cardiol Clin. 1996;14:51-68.

22. Hammond EC, Horn D. Smoking and death rates--report on forty-four months of follow-up of 187,783 men. By E. Cuyler Hammond and Daniel horn, 1958. CA Cancer J Clin. 1988;38:28-58.

23. Kianoush S, Yakoob MY, Al-Rifai M, et al. Associations of cigarette smoking with subclinical inflammation and atherosclerosis: ELSA-Brasil (the Brazilian longitudinal study of adult health). J Am Heart Assoc. 2017;6:e005088.

24. Le Bras A. Public health: light smoking and CVD risk. Nat Rev Cardiol. 2018; 15(3):136.

25. Burke GM, Genuardi M, Shappell H, et al. Temporal associations between smoking and cardiovascular disease, 1971 to 2006 (from the Framingham heart study). Am J Cardiol. 2017;120:1787-91.

26. Yusuf S, Hawken S, Ounpuu S, et al. Effect of potentially modifiable risk factors associated with myocardial infarction in 52 countries (the INTERHEART study): case-control study. Lancet. 2004:364:937-52.

27. Helgadottir A, Gretarsdottir S, Thorleifsson G, et al. Variants with large effects on blood lipids and the role of cholesterol and triglycerides in coronary disease. Nat Genet. 2016;48:634-9.

28. Lu H. A. Daugherty, atherosclerosis. Arterioscler Thromb Vasc Biol. 2015;35: 485-91

29. Yang SH, Du Y, Li XL, et al. Triglyceride to high-density lipoprotein cholesterol ratio and cardiovascular events in diabetics with coronary artery disease. Am J Med Sci. 2017;354:117-24.

30. Wu H, Xiong $L, X u Q$, et al. Higher serum triglyceride to high-density lipoprotein cholesterol ratio was associated with increased cardiovascular mortality in female patients on peritoneal dialysis. Nutr Metab Cardiovasc Dis. 2015;25:749-55.

31. Merhi M, Demirdjian S, Hariri E, et al. Impact of inflammation, gene variants, and cigarette smoking on coronary artery disease risk. Inflamm Res. 2015;64: 415-22

32. Wu Y, Song P, Zhang W, et al. Activation of AMPKa2 in adipocytes is essential for nicotine-induced insulin resistance in vivo. Nat Med. 2015;21: 373-82.

33. Kafadar D, Dogan FG, Oren MM, et al. Association of sociodemographic profile, dyslipidemias, and obesity in smoker, former smoker, and nonsmoker patients with coronary artery disease. Niger J Clin Pract. 2018:21: 1190-7.

34. Kamceva G, Arsova-Sarafinovska Z, Ruskovska T, et al. Cigarette smoking and oxidative stress in patients with coronary artery disease. Open Access Maced J Med Sci. 2016;4:636-40.

35. Thomas GN, Chook P, Yip TW, et al. Smoking without exception adversely affects vascular structure and function in apparently healthy Chinese: implications in global atherosclerosis prevention. Int J Cardiol. 2008;128: $172-7$.

\section{Publisher's Note}

Springer Nature remains neutral with regard to jurisdictional claims in published maps and institutional affiliations.
Ready to submit your research? Choose BMC and benefit from:

- fast, convenient online submission

- thorough peer review by experienced researchers in your field

- rapid publication on acceptance

- support for research data, including large and complex data types

- gold Open Access which fosters wider collaboration and increased citations

- maximum visibility for your research: over $100 \mathrm{M}$ website views per year

At BMC, research is always in progress.

Learn more biomedcentral.com/submissions 